\title{
Newer clinical strategies for combining interferon and cytotoxic agents against solid tumours and hematological malignancies
}

\author{
SCOT WADLER MD
}

\begin{abstract}
S WADLER. Newer clinical strategies for combining interferon and cytotoxic agents against solid tumours and hematological malignancies. Can $J$ Infect Dis 1994:5(Suppl A):17A-22A. The role of interferons in the treatment of cancer continues to evolve. Despite limited single agent activity against solid tumours, interferons now appear to have an important role as modulators of the activity of a variety of cytotoxic drugs. Clinical benefits have been observed for combinations of interferons and alkylating agents against low grade lymphomas, interferons and dacarbazine against malignant melanoma, and interferons and 5-fluorouracil against gastrointestinal and genitourinary malignancies. Further progress will depend on a greater understanding of the biology of the interaction.
\end{abstract}

Key Words: Biochemical modulation, Interferon, Solid tumours

\section{Stratégies cliniques récentes pour l'association d'interféron et d'agents cytotoxiques contre les fumeurs solides et les affections hématologiques malignes}

RÉSUMÉ : Le rôle des interférons dans le traitement du cancer continue d’èvoluer. Malgré l'activité limitée des agents simples contre les tumeurs solides, les interférons semblent désormais exercer un rôle important à titre de modulateurs de l'activité de divers médicaments cycotoxiques. Les avantages cliniques ont été observés pour ce qui est d'associations d'interféron et d'agents alkylants, contre des lymphomes de faible degré, d'interféron et de dacarbazine contre le mélanome malin et d'interférons et de 5-fluorouracil contre les cancers gastro-intestinaux et génito-urinaires. L'êvolution des connaissances dépendra d'une meilleure comprêhension de la biologie de ces interactions.

Albert Einstein Cancer Center and the Department of Oncology, Montefiore Medical Center, Bronx, New York, USA

Correspondence and reprints: Dr Scott Wadler, Department of Oncology, Montefiore Medical Center, 111 East 210 th Street.

Bronx, NY 10467, USA 
$\mathrm{T}$ He Ultimate UTILITY OF INTERFERONS (IFN) IN CLINICAL. cancer therapy remains unclear. Discovered in 1957 by Isaacs and Lindenmann, IFNs have undergone successive roles as antiviral agents, antiproliferative agents and biological response modifiers. Despite a paucity of information regarding their mechanism of action, the observation that IFN- $\alpha$ therapy induced prolonged clinical remission in patients with hairy cell leukemia resulted in great hopes for IFNs as anticancer agents. With the exception of modest single agent activity against Kaposi's sarcoma, melanoma and renal cell carcinoma, the utility of single agent IFN against solid tumours was never realized (1). Recently, however, both preclinical and clinical data have suggested that the greatest utility of IFNs may be their use in combination with cytotoxic agents. This paper reviews the data supporting such a role for IFNs.

\section{PRECLINICAL DATA}

IFNs represent a family of molecules that are clearly not interchangeable. Any discussion of the role of IFNs employed in combination with cytotoxic drugs must take into account the diversity of this family of glycoproteins as this is important when analyzing IFN interactions in a historical perspective. Furthermore, the complexity of IFN actions must be well understood in terms of attempting to define a hypothesis for the interaction of IFNS and cytotoxic agents at the cellular level.

Originally classified according to their source as leukocyte, fibroblast and immune IFNs, more recent nomenclature is based on sequencing (2). IFN- $\alpha$ was originally described as leukocyte IFN, IFN- $\beta$ as fibroblast IFN and IFN- $\gamma$ as immune IFN. There are at least 18 IFN- $\alpha$ nonallelic genes; together with the IFN- $\beta$ genes, these constitute an IFN- $\alpha / \beta$ superfamily of genes on chromosome 9. The IFN- $\gamma$ gene is located on chromosome 17 . IFN- $\alpha$ and IFN- $\beta$, the type 1 IFNS, and IFN- $\gamma$, the type 2 IFN, share a variety of features. These include: activity mediated via a cell surface receptor; a complex signal transduction mechanism involving preformed cytoplasmic proteins; binding of these proteins to an IFN-sensitive response element on the cell genome; and up- or down-regulation of a variety of IFN-stimulated genes (3).

The actions and effects of type 1 and type 2 IFNs are distinct, however (4) (Table 1). Therefore, it is unlikely that all classes of IFNS will interact with cytotoxic agents in precisely the same fashion. Type 1 and type 2 IFNS have unique cell surface receptors. Pathways of signal transduction differ between IFN- $\alpha$ and IFN- $\gamma$, with differential tryosine phosphorylation of various cytoplasmic proteins and possibly different kinases employed for the different ligand specific pathways. Therefore, cytotoxic drugs with strong effects on membranes, such as doxorubicin, may interact differently with type 1 and type 2 IFNS. Furthermore, the DNA binding site for IFN- $\alpha$
TABLE 1

Cellular actions of type 1 and type 2 interferons

\begin{tabular}{lcc}
\hline & Type 1: IFN- $\alpha / \beta$ & Type 2: IFN- $\gamma$ \\
\hline Unique receptor & $\times$ & $x$ \\
Induces ISG 15, 1-16 & $x$ & \\
Induces MHC class 2 & & $x$ \\
Induces 2, 5' OAS & $x$ & $?$ \\
Unique promoter & $x$ & $?$ \\
Location of IRE & $\times$ & $?$ \\
Additional promoters & $x$ & \\
\hline
\end{tabular}

IFN Interferon: IRE Interferon-stimulated response element; ISG Immune serum globulin: MHC Major histocompatibility complex; OAS 2, 5'-oligoadenylate synthetase

\section{TABLE 2}

Strategies for combining interferons with cytotoxic drugs

\begin{tabular}{l} 
Combinations with drugs for which there is evidence for \\
synergy \\
5-fluorouracil \\
Cisplatin \\
Doxorubicin \\
Cyclophosphamide \\
Diseases in which interferon and a drug have activity \\
Melanoma (plus dacarbazine) \\
Renal cell carcinoma (plus vinblastine) \\
Low to intermediate grade lymphoma (plus alkylator) \\
Chronic myelocytic leukemia (plus hydroxyurea) \\
\hline
\end{tabular}

activated proteins, termed the IFN-stimulated response element, and the protein complex that contacts the DNA binding site differ from that for IFN- $\gamma$, termed the gamma-activated site and the gamma-activated factor. While some IFN-stimulated genes are regulated by both IFN- $\alpha$ and IFN- $\gamma$, others are differentially regulated. Thus, cytotoxic drugs that act against cellular proteins or interact with a variety of cellular proteins may interact differently in cells treated with different classes of IFNS. In conclusion, it is clear that type 1 and type 2 IFNs are not interchangeable.

Recognition of these differences is critical in interpreting the results of studies employing combinations of IFNs and cytotoxic agents (7). Failure to recognize these differences could lead to premature rejection of IFN-cytotoxic combinations without fully testing the spectrum of available IFNs.

\section{IFNS AS MODULATORS OF CYTOTOXIC AGENTS}

Early in vitro models employing murine leukemia cells as tumour targets demonstrated that IFNS were capable of enhancing the cytotoxic effects of cisplatin, melphalan and cyclophosphamide. In the early 1980s, Balkwill and colleagues (5) employed a tumour model system of human breast or non-small cell lung tumours explanted to immunodeficient mice and demonstrated synergy in vivo for IFN- $\alpha$ in combination with doxorubicin, cyclophosphamide or cisplatin. There were several important findings from these studies. First, given 
TABLE 3

Interferon plus dacarbazine in melanoma

\begin{tabular}{|c|c|c|c|c|}
\hline Institution (Reference) & Number & Regimen & Objective response rate (\%) & Comments \\
\hline Brisbane (8) & 51 & $\begin{array}{l}\text { DTIC } 200-800 \mathrm{mg} / \mathrm{m}^{2} \mathrm{q} 3 \mathrm{w} \\
\text { IFN 3-9x106 U/day }\end{array}$ & 32 & \\
\hline Milan (9) & 75 & $\begin{array}{l}\text { DTIC } 800 \mathrm{mg} / \mathrm{m}^{2} \mathrm{q} 3 \mathrm{w} \\
\text { IFN 3-9x10 } 10^{6} \mathrm{day}\end{array}$ & 25 & $8 \%$ complete response \\
\hline \multirow[t]{3}{*}{ Schering (10) } & 24 & DTIC $250 \mathrm{mg} / \mathrm{m}^{2} \times 5 \mathrm{q} 3 \mathrm{w}$ & 21 & \\
\hline & 23 & IFN $30 \times 10^{6} \mathrm{U} \times 5$ weekly & 4 & Trial terminated \\
\hline & 21 & $\mathrm{IFN}+\mathrm{DTIC}$ & 19 & \\
\hline \multirow[t]{2}{*}{ Pretoria (11) } & 31 & DTIC $200 \mathrm{mg} / \mathrm{m}^{2} \times 5 \mathrm{q} 3 \mathrm{w}$ & 19 & $\begin{array}{l}\text { Overall survival } 18 \text { versus } 10 \\
\text { months }\end{array}$ \\
\hline & 32 & + IFN $15 \times 10^{6} \mathrm{U} / \mathrm{m}^{2} \times 5$ & 50 & $\begin{array}{l}\text { Objective responses in liver } \\
38 \% \text { complete response } \\
\text { (+IFN) }\end{array}$ \\
\hline Helsinki (29) & 48 & $\begin{array}{l}\text { DTIC } 200 \mathrm{mg} / \mathrm{m}^{2} \times 5 \\
\text { VCR } 1 \mathrm{mg} / \mathrm{m}^{2} \text { day } 1 \text { and } 4 \\
\text { Bleo } 15 \mathrm{mg} \text { day } 2 \text { and } 5 \\
\text { CCNU } 80 \text { day } 1 \\
\text { IFN } 3-6 \times 10^{6} \mathrm{U} / \text { day }\end{array}$ & 62 & $\begin{array}{l}\text { Objective responses in liver } \\
13 \% \text { complete response }\end{array}$ \\
\hline Finland (30) & 52 & $\begin{array}{l}\text { DTIC } 250 \mathrm{mg} / \mathrm{m}^{2} \times 5 \\
\text { Nimustine } 1 \mathrm{mg} / \mathrm{kg} \\
\text { IFN 3-5x } 10^{6} \mathrm{U} 3 / \text { week }\end{array}$ & 23 & $\begin{array}{l}\text { Objective responses in liver } \\
17 \% \text { complete response }\end{array}$ \\
\hline
\end{tabular}

Bleo Bleomycin; CCNU ChloroethylcyclohexyInitrosourea; DTIC Dacarbazine: IFN Interferon; q3w Every three weeks; VCR Vincristine

that the mice were immunodeficient, it was likely that the IFN effects were mediated at the biochemical level rather than via immune stimulation. Second, studies of IFN effects in the cytochrome p450 system suggested that the IFN effects were not mediated by altering activation or catabolism of the cytotoxic drugs via hepatic p450 cytochromes. Third, several experiments demonstrated the schedule dependency of this interaction, with simultaneous administration of IFN plus cyclophosphamide being more effective than sequential administration. This latter observation has been amplified recently in detailed studies employing a P388 murine leukemia model; the survival benefits were dependent on the timing of administration of IFN and cyclophosphamide (6). Since publication of these early studies, synergy or additivity of IFN with over 30 different cytotoxic agents in vitro or in vivo has been demonstrated against a variety of tumour model systems. These have been reviewed extensively in previous manuscripts (7).

\section{CLINICAL STRATEGIES FOR COMBINING IFNS AND CYTOTOXIC AGENTS}

Two major strategies have emerged from studies combining IFNs with cytotoxic agents (Table 2). In the first group, IFNS and cytotoxic drugs are combined against tumours for which both IFN and the cytotoxic drug have known antitumour activity. In the second group, IFNs have been combined with agents such as 5-fluorouracil, cisplatin or cyclophosphamide for which there is good evidence for synergy in preclinical tumour models. Examples of both strategies are discussed below.

\section{COMBINATIONS IN WHICH BOTH IFN AND A CYTOTOXIC DRUG HAVE INDEPENDENT ACTIVITY}

Single agent IFNS are active against a variety of solid tumours, primarily renal cell carcinoma and melanoma, as well as low grade lymphomas and chronic myelocytic leukemia (1).

Thus, it is natural to employ them in combination with single agent cytotoxic drugs or with combination chemotherapy against these malignancies.

Renal cell carcinoma: Both IFN and vinblastine have modest activity. This combination has been employed in a variety of schedules with no improvement observed over what would be expected with either vinblastine or IFN employed separately (7).

Melanoma: Both IFN and dacarbazine (DTIC) have response rates in the 15 to $20 \%$ range against metastatic malignant melanoma (1). Early studies from Australia (8) and Italy (9) failed to show a benefit for the combination (Table 3). Furthermore, a randomized trial of IFN, DTIC or the combination was terminated administratively after very early results failed to demonstrate a benefit (10). In a prospective randomized phase 3 trial from South Africa (11) of DTIC versus DTIC plus IFN, the objective response rate for the combination (50\% versus $19 \%$ for DTIC alone) was significantly better, objective responses were observed in viscera as well as soft tissues, and the combination produced a 38\% complete response rate. Furthermore, there was a survival advantage for the combination that was statistically significant. Two studies from Scandinavia of IFN plus combinations of cytotoxic drugs have produced conflicting results (Table 3 ). 
TABLE 4

Interferon plus alkylating agents in follicular and low grade lymphomas

\begin{tabular}{lcll}
\hline Institution (reference) & Number & Regimen & Comments \\
\hline ECOG (12) & 291 & COPA versus I-COPA & Increased response duration, time to failure \\
MD Anderson (31) & 127 & CHOP-Bleo \pm IFN & Failure free survival 60\% versus $38 \%$ historical controls \\
St Barts (32) & 160 & Chl versus Chl-I & Longer response duration for ChI-I \\
EORTC (33) & 231 & CVP \pm IFN (maintenance) & Longer progression free survival \\
GELA (34) & 230 & CHVP \pm IFN & Improved objective response, complete response, \\
& & disease free survival and overall survival with IFN \\
\hline
\end{tabular}

Bleo Bleomycin; Chl Chlorambucil; CHOP Cyclophosphamide, hydroxydaunomycin, vincristine, prednisone; CHVP Cyclophosphamide, hydroxydaunorubicin (Adriamycin), vincristine, prednisone: COPA Cyclophosphamide, vincristine, prednisone, doxorubicin: CVL Cyclophosphamide, vincristine, prednisone; ECOG Eastern Cooperative Oncology Group; EORTC European Organization for Research and Treatment in Cancer; GELA Groupe d'Études des Lymphomes de I'Adulte; IFN Interferon; St Barts St Bartholomew's Hospital, London

In contrast, studies of IFN plus cisplatin against melanoma have resulted in response rates that are similar to those observed with IFN alone, despite substantial evidence in preclinical systems for synergy (12). The lack of antitumour effect may have resulted in part from the difficulty in administering these regimens because of substantial toxicities.

Low grade lymphoma: Use of IFNS in combination with alkylating agent-based regimens against low or intermediate grade lymphomas blends strategies employing IFNS with drugs that have activity against a selected tumour and employing IFNS in combinations for which there is evidence for synergy.

Early studies employing small numbers of patients suggested a benefit in terms of response rate and progression-free survival for the combination of IFN and chlorambucil in patients with follicular lymphomas. IFN as maintenance therapy did not appear to be beneficial.

In 1988 the Eastern Cooperative Oncology Group (ECOG) conducted a randomized trial comparing cyclophosphamide, vincristine, prednisone and doxorubicin without (COPA) or with (I-COPA) IFN- $\alpha$ (13). Patients were required to have stage 3 to 4 intermediate grade disease or low grade disease with unfavourable features (B symptoms, bulky disease or rapid doubling times). The toxicities were comparable in both arms with a slightly higher incidence of infection in the copA group and a higher incidence of fevers and neurological symptoms in the I-COPA group. Treatment with the IFN-containing regimen resulted in comparable objective and complete response rates, but prolonged time to treatment failure, duration of complete response and overall survival. This occurred despite significant reductions in the doses of cyclophosphamide and doxorubicin received by patients in the I-COPA group $(76 \%$ of planned dose versus $96 \%$ of planned dose among patients receiving COPA).

Subsequent trials of IFNS and alkylating agents in low grade lymphomas are shown in Table 4 . While not definitive, these trials tend to show an advantage for the combination therapy.

Chronic myelocytic leukemia: Preliminary data from Australia (14) and MD Anderson (15) suggest a higher incidence of cytogenetic complete responses with the combination of IFN plus hydroxyurea than with either agent alone. This remains to be confirmed in larger trials.

\section{COMBINATIONS OF IFNS AND CYTOTOXIC AGENTS FOR WHICH THERE IS EVIDENCE FOR SYNERGY IN PRECLINICAL SYSTEMS}

IFNS have been demonstrated to be synergistic with over 30 cytotoxic drugs in preclinical systems. Evidence of synergy for combinations of IFN with 5-fluorouracil (5FU), cisplatin (CDDP) and doxorubicin, among others, is extensive and suggests the potential for clinical benefits (7). The experience with IFN plus CDDP was discussed above. There was no suggestion of benefit against melanoma, and the combination was toxic. Likewise, the combination of IFN plus doxorubicin in phase 1 trials demonstrated excessive myelosuppression, and there were also several instances of acute cardiac toxicities, including myocardial infarction. This combination has not been extensively studied (except in combination regimens such as I-COPA). The combination of IFN plus $5 \mathrm{FU}$ is the best studied employing this strategy.

Fluorouracil plus interferon: Based on in vitro data against human colon cancer cell lines, early clinical trials of $5 \mathrm{FU}$ plus IFN were initiated at the Albert Einstein College of Medicine (AЕCOM) in 1988. A phase 1 trial in patients with colorectal cancer employing 5Fu, $750 \mathrm{mg} /$ $\mathrm{m}^{2}$ /week plus IFN at 3 to $18 \times 10^{6} \mathrm{U}$ daily demonstrated that the maximum tolerated dose for IFN was 15 to $18 \times 10^{6} \mathrm{U}$ daily, but with substantial fatigue (16). Furthermore, among the patients treated at the lower doses of IFN, there was a $56 \%$ objective response rate with one complete responder, whereas, at the higher dose level, there were no responders. Based on these data and data from a phase 2 study in England that employed high dose IFN and low dose 5FU, and which resulted in a response rate of less than $10 \%$ in advanced colorectal cancer, investigators at AECOM initiated a phase 2 trial employing intermediate doses of both IFN and 5FU (17).

A phase 2 trial employing the AECOM regimen resulted in a response rate of $63 \%$, but with formidable toxicities, including three toxic deaths (two with watery 
TABLE 5

\begin{tabular}{l}
$\begin{array}{l}\text { Phase } 2 \text { clinical trials with the combination of intermedi- } \\
\text { ate dose 5-fluorouracil and recombinant interferon- } \alpha^{*}\end{array}$ \\
\hline \begin{tabular}{lcc} 
Institution (reference) & Number & Objective response (\%) \\
\hline AECOM (18) & 32 & $20(63)$ \\
NE Deaconess (35) & 8 & $3(38)$ \\
MD Anderson (36) & 22 & $7(32)$ \\
MSKCC (37) & 34 & $9(26)$ \\
ECOG (21) & 36 & $15(42)$ \\
Padua (38) & 21 & $9(43)$ \\
Madrid (39) & 33 & $8(24)$ \\
Nantes (40) & 16 & $5(31)$ \\
Total & 202 & $76(38)$
\end{tabular}
\end{tabular}

*This includes only those studies employing the intermediate-dose 5-fluorouracil/interferon regimen used in the Albert Einstein study. AECOM Albert Einstein College of Medicine; ECOG Eastern Cooperative Oncology Group: MSKCC Memorial Sloan-Kettering Cancer Center

diarrhea followed by sepsis). A subsequent ECOG trial (18) with the same regimen, but more stringent dose modification criteria, demonstrated the efficacy and tolerability of this regimen. Among eight clinical trials employing the AECOM regimen, the overall response rate has been 38\% (Table 5). Preliminary results from recently completed phase 3 trials of $5 \mathrm{FU} / \mathrm{IFN}$ versus $5 \mathrm{FU} /$ leucovorin, and 5FU/IFN versus 5FU alone $(19,20)$, have yielded confusing results, but suggest that combination therapy may be less active than earlier reports suggest. Interpretation of these trials awaits reporting of the full results.

Trials in patients with esophageal carcinoma $(21,22)$ and in patients with bladder cancer, who had failed a cisplatin-containing regimen (23), also demonstrated substantial activity. In the АЕсом trial, there were two complete responders, including one patient who was

\section{REFERENCES}

1. Wadler S. The role of interferons in the treatment of solid tumors. Cancer 1992;70:949-58.

2. Sen GC, Lengyel P. The interferon system: A bird's eye view of its biochemistry. J Biol Chem 1992;267:5017-20.

3. Schindler C, Shuai K, Prezioso V, Darnell JE. Interferondependent tyrosine phosphorylation of a latent cytoplasmic transcription factor. Science 1992;257:809-15.

4. Shuai K, Schindler C, Prezioso VR, Darnell JE. Activation of transcription by IFN- $\gamma$ : Tyrosine phosphorylation of a 91 kd DNA binding protein. Science 1992;258:1808-12.

5. Balkwill FR, Moodie EM. Positive interactions between human interferon and cyclophosphamide or Adriamycin in a human tumor model system. Cancer Res 1984;44:904-8.

6. Borden EC, Sidky YA, Hatcher JF, Bryan GT.

Schedule-dependent variations in the response of murine P388 leukemia to cyclophosphamide in combination with interferon $\alpha / \beta$. Cancer Res 1988;48:2329-34.

7. Wadler S, Schwartz EL. Antineoplastic activity of the combination of interferon and cytotoxic agents against experimental and human malignancies: A review. Cancer Res 1990;50:3473-86.

8. Thomson DB, McLeod RC, Hersey P. Phase I/II study of tolerability and efficacy of recombinant interferon (Roferon) with dacarbazine (DTIC) in advanced malignant rendered operable and remains free from disease after two years.

Two mechanisms of interaction between $5 \mathrm{FU}$ and IFN have been studied. In vitro studies against human colon cancer cell lines and a murine adenocarcinoma cell line have demonstrated synergistic cytotoxicity for the combination which is reversed by exogenous thymidine, suggesting that the combination is acting primarily at the level of the 5Fu target enzyme, thymidylate synthase (24). IFN appears capable of reversing a $5 \mathrm{FU}$-induced elevation in thymidylate synthase levels, possibly acting at the post-transcriptional level. Furthermore, IFN enhances 5FU-induced depletion of thymidine triphosphate pools, and treatment with the combination resulted in an increase in DNA double strand breaks compared with $5 \mathrm{FU}$ alone (25). These data remain preliminary.

In clinical trials, IFN treatment resulted in an increase in plasma levels of $5 \mathrm{FU}$ in patients receiving intermediate dose bolus or infusional therapy $(26,27)$. In some studies this was dependent on the dose of IFN employed, although this was not invariable. Furthermore, the reduced folate, leucovorin, partially reversed the pharmacokinetic benefits of IFN in some studies, which appeared to result from a decrease in $5 \mathrm{FU}$ catabolism (28).

\section{CONCLUSION}

Combinations of IFNs and cytotoxic agents have resulted in improvements in objective response rates, time to failure and overall survival in various clinical trials. In the case of IFN plus 5FU, mechanisms of interaction have been described in detail. The relative importance of each remains to be determined. Further studies of IFN-cytotoxic combinations are warranted.

melanoma (MM). Proc Am Soc Clin Oncol 1987;6:208.

9. Bajetta E, Negretti E, Giannotti B, et al. Phase II study of interferon alpha-2a (rIFN alpha-2a) and dacarbazine (DTIC) in metastatic melanoma (MM). Proc Am Soc Clin Oncol 1989;8:286.

10. Kirkwood JM, Ernstoff MS, Giuliano A, et al. Interferon $\alpha-2 \mathrm{a}$ and dacarbazine in melanoma. $\mathrm{J}$ Natl Cancer Inst 1990:82:1062-3.

11. Falkson C, Falkson G, Falkson HC. Improved results with the addition of interferon alfa- $2 b$ to dacarbazine in the treatment of patients with metastatic malignant melanoma. J Clin Oncol 1991;9:1403-8.

12. Walsh CM, Speyer JL, Wernz J, et al. Phase I study of the combination of $\alpha 2$ interferon and cisplatinum. J Biol Resp Modif 1989;8:11-5.

13. Smalley RV, Anderson JW, Hawkins MJ, et al. Interferon alfa combined with cytotoxic chemotherapy for patients with non-Hodgkin's lymphoma. N Engl J Med 1992;327: 1336-41.

14. Taylor K, Eliadis P, Elliott S, et al. Alpha-interferon $(\alpha$-IFN)/hydroxyurea (HU) therapy in newly diagnosed chronic myeloid leukemia (CML) between age 20 and 50 . Proc Am Soc Clin Oncol 1992;1 1:268.

15. Talpaz M, O'Brien S, Kurzrock R, et al. Alpha interferon (IFN- $\alpha$ ) and chemotherapy combination in early chronic 
myelogenous leukemia (CML) - A summary of $3 \mathrm{MD}$ Anderson studies. Proc Am Soc Clin Oncol 1992;11:274.

16. Wadler S, Goldman M, Lyver A, Wiernik PH. A phase I trial of 5-fluorouracil and recombinant alpha-2a-interferon in patients with gastrointestinal malignancies. Cancer Res 1990;50:2056-9.

17. Wadler S, Wiernik PH. Clinical update on the combination of 5-fluorouracil and recombinant alpha-2a-interferon in the treatment of colorectal carcinoma. Semin Oncol 1990;17:16-21.

18. Wadler S, Lembersky B, Kirkwood J, Atkins M, Petrelli M. Phase II trial of fluorouracil and recombinant alfa-2a-interferon in patients with advanced colorectal carcinoma: An Eastern Cooperative Oncology Group study. J Clin Oncol 1991;9:1806-10.

19. York M, Greco FA, Figlin RA, et al. A randomized phase III trial comparing 5-FU with or without interferon alfa $2 \mathrm{a}$ for advanced colorectal cancer. Proc Am Soc Clin Oncol 1993; 12:200.

20. Koch W. 5-fluorouracil (5FU) plus interferon alpha-2a (Roferon-A) versus 5-fluorouracil plus leucovorin (LV) in metastatic colorectal cancer - Results of a multicentre multinational phase III study. Proc Am Soc Clin Oncol 1993; $12: 193$

21. Wadler S, Fell S, Haynes H, et al. Treatment of carcinoma of the esophagus with 5-fluorouracil and recombinant alfa-2a-interferon. Cancer 1993;71:1726-30.

22. Kelsen D. Lovett D, Wong J, et al. Interferon alfa-2a and fluorouracil in the treatment of patients with advanced esophageal cancer. J Clin Oncol 1992;10:269-74.

23. Logothetis CJ, Hossan E, Sella A, Dexeus FH, Amato RJ. Fluorouracil and recombinant human interferon alfa-2a in the treatment of metastatic chemotherapy-refractory urthelial tumors. J Natl Cancer Inst 1990;83:285-7.

24. Elias L, Crissman HA. Interferon effects upon the adenocarcinoma 38 and HL-60 cell lines: Antiproliferative responses and synergistic interactions with halogenated pyrimidine antimetabolites. Cancer Res 1988;48:4868-73.

25. Wadler S, Mao X, Schwartz EL. Recombinant alfa-2a-interferon (IFN) augments 5-fluorouracil (5FU) effects on nucleotide (dNTP) pools and DNA double strand breaks (dsb) in human colon cancer cell lines. Proc Am Assoc Cancer Res 1992:33:425.

26. Grem JL, McAtee N, Murphy RF, et al. A pilot study of interferon alfa- $2 \mathrm{a}$ in combination with fluorouracil plus high-dose leucovorin in metastatic gastrointestinal carcinoma. J Clin Oncol 1991;9:1811-21.

27. Danhauser L, Gilchrist T, Friemann J, et al. Effect of recombinant interferon- $\alpha 2 \mathrm{~b}$ on the plasma pharmacokinetics of fluorouracil in patients with advanced cancer. Proc Am Assoc Cancer Res 1991;32:176.

28. Schuller J, Czejka M, Miksche M, et al. Influence of interferon $\alpha 2 \mathrm{~b}$ (IFN) \pm leucovorin (LV) on pharmacokinetics (PK) of 5-fluorouracil. Proc Am Soc Clin Oncol 1991;10:98.

29. Pyrhonen S, Hahka-Kemppinen M, Muhonen T. A promising interferon plus four-drug chemotherapy regimen for metastatic melanoma. J Clin Oncol 1992;10:1919-26.

30. Grohn P, Kumpulainen E, Nuortio L, et al. A phase II study of metastatic melanoma treated with a combination of interferon alfa2b, dacarbazine, and nimustine. Eur $J$ Cancer 1992;28:441-3.

31. McLaughlin P, Cabanillas F, Hagemeister FB, et al. CHOP-Bleo plus interferon for stage IV low grade lymphoma. Ann Oncol 1993;4:205-11.

32. Price CGA, Rohatiner AZS, Steward W, et al. Interferon-alfa $2 \mathrm{~b}$ in the treatment of follicular lymphomas: Preliminary results of a trial in progress. Ann Oncol 1991;2(Suppl 2):141-5.

33. Hagenbeck A, Carde P, Somers R, et al. Maintenance remission with human recombinant alpha-2 interferon (Roferon A) in patients with stages III and IV low grade malignant non-Hodgkins lymphoma. Results from a prospective, randomized phase III clinical trial in 331 patients. Blood 1992;80(Suppl I):288.

34. Solal-Celigny P, Lepage E, Brousse N, et al. Recombinant interferon alfa- $2 \mathrm{~b}$ combined with a regimen containing doxorubicin in patients with advanced follicular lymphoma. N Engl J Med 1993;329:1608-14.

35. Huberman M, McClay E, Atkins M, et al. Phase II trial of 5-fluorouracil (5FU) and recombinant interferon alpha $2 \mathrm{a}$ (IFN) in advanced colorectal cancer. Proc Am Soc Clin Oncol 1991; 10:478.

36. Pazdur R, Ajani JA, Patt YZ, et al. Phase II study of fluorouracil and recombinant interferon alfa-2a in previously untreated advanced colorectal carcinoma. $\mathrm{J}$ Clin Oncol 1990;8:2027-31.

37. Kemeny N, Younes A, Seiter K, et al. Interferon alpha-2a and 5-fluorouracil for advanced colorectal carcinoma. Assessment of activity and toxicity. Cancer 1990;66:2470-5.

38. Fornasiero A, Daniele O, Ghiotto C, Aversa SM, Morandi $\mathrm{P}$, Fiorentino MV. Alpha-2 interferon and 5-fluorouracil in advanced colorectal cancer. Tumori 1990;76:385-8.

39. Diaz-Rubio E, Jimeno J, Camps C, et al. Treatment of advanced colorectal cancer with recombinant interferon-alfa and fluorouracil: Activity in liver metastases. Cancer Invest 1992;10:259-64.

40. Douillard JY, Leborgene J, Danielou JY, et al. Phase II trial of 5-fluorouracil (5FU) and recombinant alpha interferon (r-alpha-ifn) (Intron A) in metastatic previously untreated colorectal cancer (crc). Proc Am Soc Clin Oncol $1991 ; 10: 422$. 


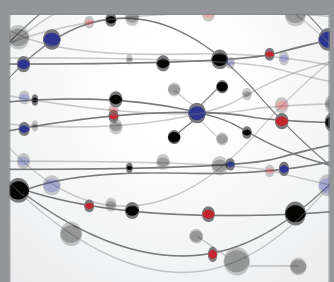

The Scientific World Journal
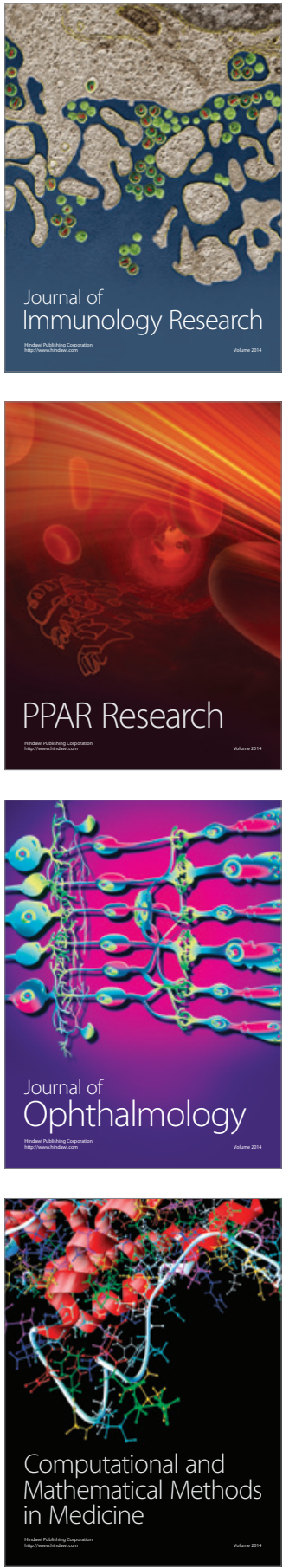

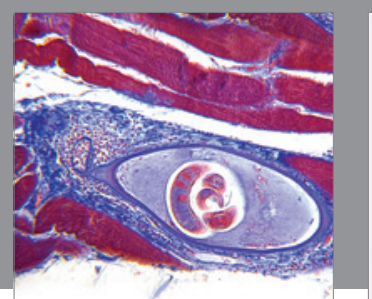

Gastroenterology Research and Practice

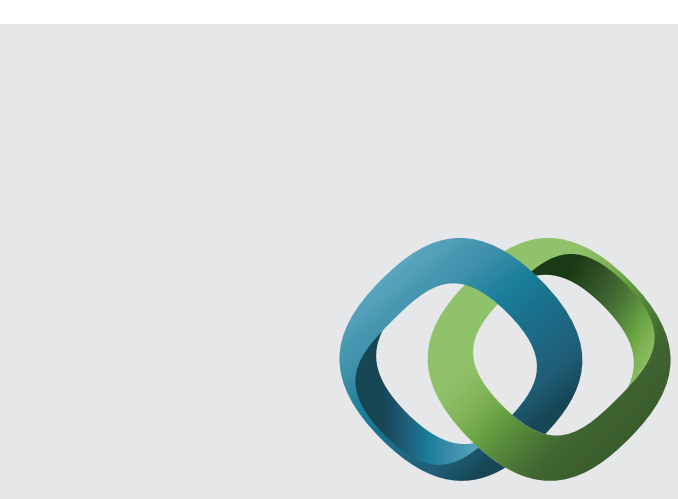

\section{Hindawi}

Submit your manuscripts at

http://www.hindawi.com
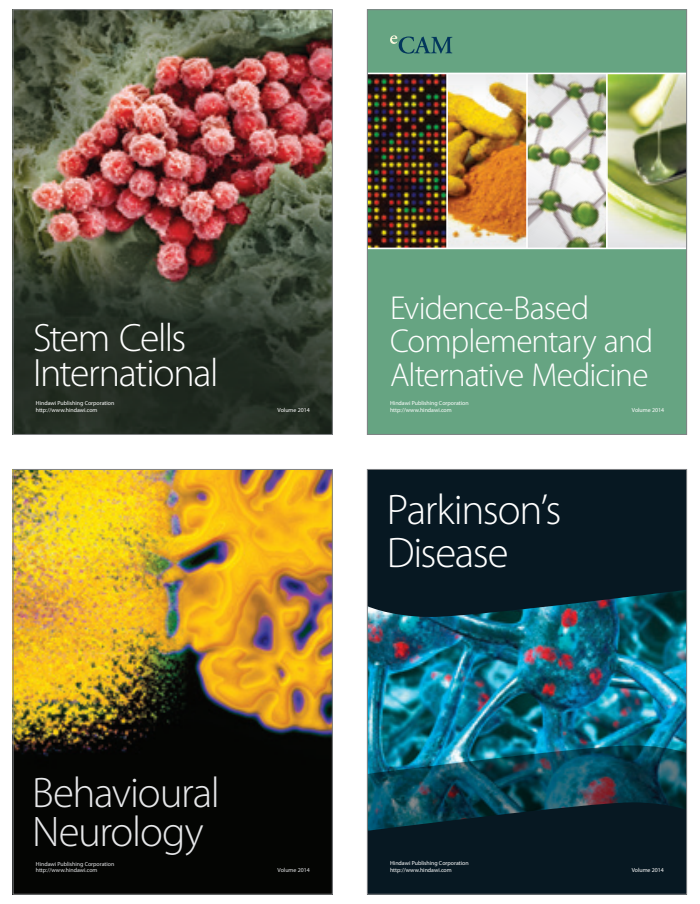
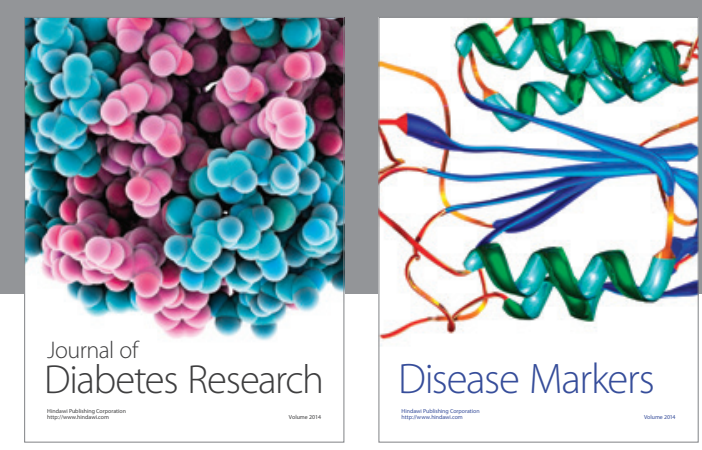

Disease Markers
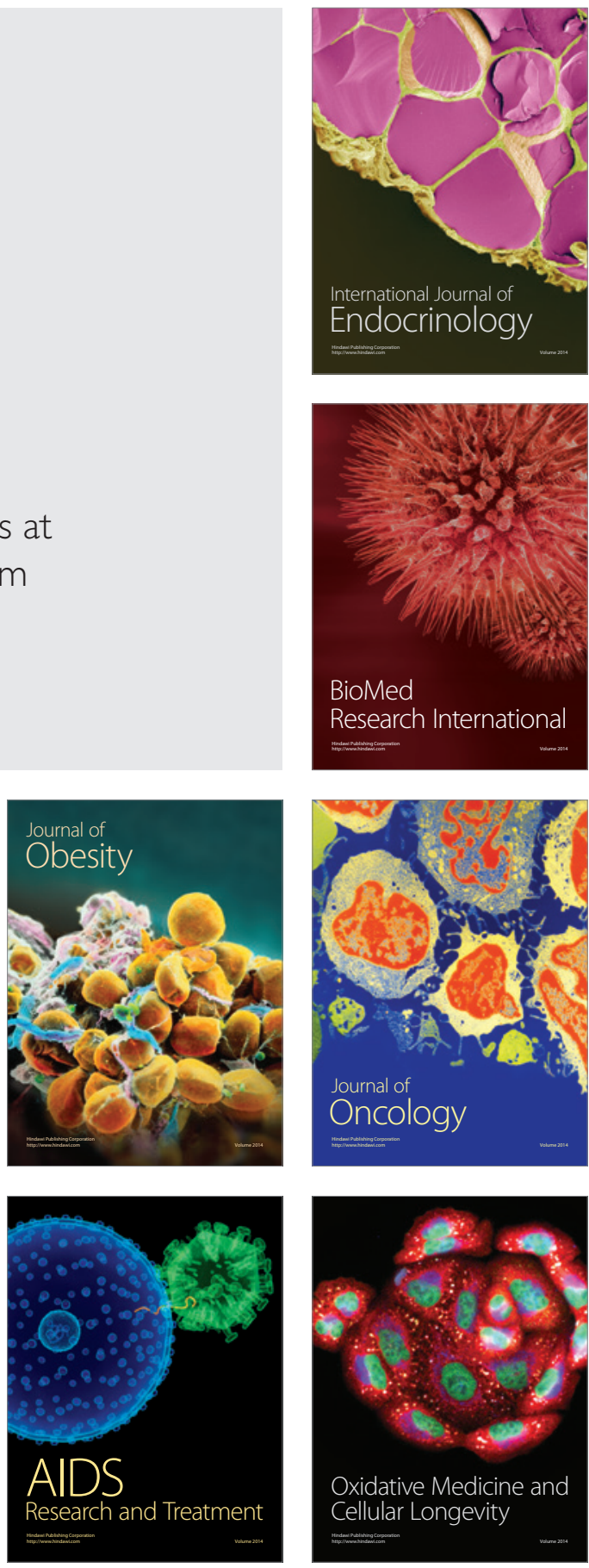